\title{
UM OLHAR SOBRE A FORMAÇÃO DO ALUNO COM DOENÇA FALCIFORME
}

\author{
A look on the education of students with sickle cell disease
}

Una mirada sobre la formación de los estudiantes con la enfermedad de células falciformes

\section{Welma Cirqueira Cavalcante Rodrigues ${ }^{1}$, Carla Simone Seibert ${ }^{1 *}$, Kellen Lagares Ferreira da Silva ${ }^{1}$}

${ }^{1}$ Curso de Ciências Biológicas, Universidade Federal do Tocantins - Campus de Porto Nacional, Porto Nacional, Tocantins, Brasil

*Correspondência: Universidade Federal do Tocantins - Campus de Porto Nacional - Rua 03, Quadra 17, Lote 11, S/N ${ }^{o}$, Setor Jardim dos Ipês / CEP: 77500-000 / Porto Nacional - TO. E-mail: seibertc@@uftedu.br

\section{RESUMO}

A doença falciforme engloba um grupo de anemias hemolíticas hereditárias, de origem afrodescendente, que altera a forma dos glóbulos vermelhos do sangue, mudando sua forma elíptica para a de foice, quando em crise. As pessoas com doença falciforme podem apresentar crises frequentes o que prejudica as suas atividades sociais, incluindo às escolares. Com vistas a isso, a proposta do presente trabalho foi o de avaliar a importância da escola para o desenvolvimento intelectual e social do aluno com doença falciforme. Foi aplicado questionário semiestruturado para os alunos com doença falciforme e suas mães, professores, coordenadores e diretores de duas escolas estaduais do município de Monte do Carmo - TO. Os resultados evidenciaram as dificuldades dos alunos com a doença no ambiente escolar, a percepção das mães quanto à limitação do acompanhamento pedagógico das unidades de ensino com seus filhos e a falta de conhecimento dos profissionais da educação sobre o assunto. Portanto, o aluno com doença falciforme não consegue usufruir de um aprendizado satisfatório por não ter o acompanhamento adequado, o que evidencia a necessidade de uma formação continuada para os profissionais da educação, voltada para esta temática.

Palavras-chave: hemoglobina S, professores, ensino.

\section{ABSTRACT}

Sickle cell disease encompasses a group of hereditary hemolytic anemias, of Afro-descendant origin, which changes the shape of red blood cells, changing its elliptical form to that of sickle, when in crisis. People with sickle cell disease may have frequent crisis, which impairs their social activities, including school related ones. With this in view, the purpose of this study was to evaluate the importance of the school for the intellectual and social development of students with sickle cell disease. To carry out this study a structured questionnaire was applied to students with sickle cell disease and their mothers, teachers, engineers and managers of two public schools in the city of Monte do Carmo - TO. The results evidenced students' difficulties with the disease in school environment, the perception of mothers in relation to the limited pedagogical monitoring of their children from teaching units and the lack of knowledge from education professionals about the subject. Therefore, students with sickle cell disease can't enjoy a satisfactory learning, as they don't receive proper monitoring in their cognitive, personal and school needs, which signals the need of continuous guidance for education professionals, focused on this subject.

Keywords: hemoglobin S, teachers, teaching.

\section{RESUMEN}

Enfermedad de células falciformes comprende un grupo de anemias hemolíticas hereditarias, de origen afrodescendiente, que altera la forma de las células rojas de la sangre, cambiando su forma elíptica a una hoz cuando está en crisis. Las personas con enfermedad de células falciformes pueden tener ataques frecuentes, que afectan a sus actividades socias, incluyendo la escuela. Con miras a esto, el propósito de este estudio fue evaluar la importancia de la escuela para el desarrollo intelectual y social del 
estudiante con la enfermedad de células falciformes. Cuestionario semi-estructurado se aplica a los alumnos con enfermedad de células falciformes y sus madres, profesores, coordinadores y directores de dos escuelas públicas de la ciudad de Monte do Carmo-TO. Los resultados mostraron dificultades de los estudiantes con la enfermedad en el entorno escolar, la percepción de las madres en relación con la limitación del seguimiento pedagógico de las unidades de enseñanza con sus hijos y la falta de conocimiento de los profesionales de la educación sobre el tema. Por lo tanto, los estudiantes con la enfermedad de células falciformes a menudo no pueden disfrutar de un aprendizaje satisfactorio por no contar con la supervisión adecuada, poniendo de relieve la necesidad de formación continua para los profesionales de la educación, dedicados a este tema.

Descriptores: la hemoglobina S, profesores, enseñanza.

\section{INTRODUÇÃO}

No Brasil, a defesa para a educação das pessoas com necessidades educativas especiais iniciou na Constituição Federal de 1946, quando se reconheceu o direito universal à educação (BRASIL, 1946). No ano de 1969, o Decreto Lei n ${ }^{\circ} 1.044$ definiu o tratamento especial para os alunos com afecções congênitas ou adquiridas, infecções, traumatismo ou outras condições mórbitas, caracterizados por incapacidade física relativa, incompatível com a frequiência aos trabalhos escolares. Foi incluído neste à oferta de exercícios domiciliares, com o acompanhamento escolar, para a compensação da ausência das aulas, para estes alunos.

No entanto, foi em 1996 que a educação especial foi tratada na Lei de Diretrizes e Bases da Educação Nacional, pela Lei n. 9.394, no capítulo V, Art. 59 que trata:

Art. 59 . Os sistemas de ensino assegurarão aos educandos com necessidades especiais:

I - currículos, métodos, técnicas, recursos educativos e organização específicos, para atender às suas necessidades;

II - terminalidade específica para aqueles que não puderem atingir o nível exigido para a conclusão do ensino fundamental, em virtude de suas deficiências, e aceleração para concluir em menor tempo o programa escolar para os superdotados;

III - professores com especialização adequada em nível médio ou superior, para atendimento especializado, bem como professores do ensino regular capacitados para a integração desses educandos nas classes comuns;

IV - educação especial para o trabalho, visando a sua efetiva integração na vida em sociedade, inclusive condições adequadas para os que não revelarem capacidade de inserção no trabalho competitivo, mediante articulação com os órgãos oficiais afins, bem como para aqueles que apresentam uma habilidade superior nas áreas artística, intelectual ou psicomotora;

$\mathrm{V}$ - acesso igualitário aos benefícios dos programas sociais suplementares disponíveis para o respectivo nível do ensino regular.

Diante do exposto, ressalta-se a necessidade de ampliar a discussão sobre deficiência e necessidades especiais na educação, tendo em foco as pessoas com doença falciforme (DF). Essa doença engloba um grupo de anemias hemolíticas hereditárias, que possuem em comum a presença da hemoglobina $\mathrm{S}$ (HbSS, HbSC, HbSD, ...) (ZAGO e PINTO, 2007).

A doença falciforme tem origem afrodescendente e sua principal característica é a alteração do glóbulo vermelho do sangue, células que são flexíveis e arredondadas mudam sua forma, adquirindo o formato de foice. Situações como frio, estresse, desidratação, dentre outros levam a pessoa com a doença a entrar em crise, então os glóbulos vermelhos falcizam e circulam com dificuldade pelos vasos sanguíneos, provocando diversas complicações ao organismo (NAOUM e DOMINGOS, 1997; NAOUM, 2000).

A pessoa com DF pode apresentar quadro de anemia crônica, alterações vasoclusivas, viscerais, 
hemolíticas, infarto, acidente vascular cerebral, icterícia (cor amarelada visível nos olhos) úlceras nas pernas (feridas), lesões crônicas nos órgãos e intensa sensação de dor. A dor é decorrente do acúmulo das células em "foice", e suas pontas finas fincam-se nas paredes dos vasos sanguíneos como se fossem ganchos, provocando lesões que incomodam e causam desconforto ao doente. As manifestações clínicas diferem de um indivíduo para outro, mas estas são responsáveis por dificultar a vida escolar da pessoa com DF. Já que para minimizá-las é necessário que haja acompanhamento médico, repouso e dependendo do quadro clínico, transfusões sanguíneas (PAIVA-SILVA et al., 1993; RAMALHO e MAGNA, 2003; DI NUZZO e FONSECA, 2004).

Dessa forma, em idade escolar a pessoa com DF apresenta uma variedade de sintomas causados pela doença, que muitas vezes limita sua participação nas atividades escolares, prejudicando seu rendimento (DIAS et al., 2013). Segundo KIKUCHI (2003), a pessoa com DF pode alcançar, em média, cerca de 40 a 50 dias de faltas no ano letivo, podendo elevar essa média se houverem crises mais intensas, com manifestações clínicas mais graves. Então, para diminuir os prejuízos relativos ao aprendizado, a escola precisa adotar procedimentos avaliativos diferenciados, para amparar o aluno com a doença. Esses procedimentos, além de ter o amparo legal, são de grande valia para que o aluno com a DF possa dar continuidade aos estudos.

Para tanto, faz-se necessário que os profissionais da educação tenham conhecimento sobre a doença, para melhor atendê-la e tornar possível o acesso e permanência do aluno na escola (PIRES, 2008; RODRIGUES et al., 2014). Contudo, apesar de todos os avanços na medicina e com o advento da abertura das redes sociais e da comunicação em massa, a DF ainda é pouco conhecida no âmbito escolar. Diante das informações antepostas, necessário se faz direcionar o olhar das escolas em benefício dos alunos com DF, visto a atenção especial de que necessitam. Portanto, o presente artigo tem por finalidade avaliar a importância da escola para o desenvolvimento intelectual e social do aluno com doença falciforme.

\section{MATERIAIS E MÉTODOS}

O presente trabalho foi realizado nas escolas públicas estaduais do município de Monte do Carmo, estado do Tocantins. Segundo o IBGE (2010) a cidade possui uma população estimada em 6.716 habitantes, em uma área de 3.616,67 $\mathrm{Km}^{2}$, com densidade demográfica de 1,86 habitantes $/ \mathrm{km}^{2}$.

O município possui forte influência afrodescendente, com uma comunidade quilombola reconhecida pela Fundação Cultural Palmares, Comunidade de Mata Grande (Fundação Cultural Palmares, 2016a), e outra em processo de certificação, Comunidade de Taquari (Fundação Cultural Palmares, 2016b). Estudos de diagnóstico da doença falciforme revelaram uma população com traço falciforme acima do esperado para a região norte do Brasil, e registro de pessoas com a doença que vieram a óbito (ANDRADE et al., 2014).

$\mathrm{Na}$ zona urbana do município de Monte do Carmo há 2 escolas públicas estaduais: a Escola Estadual de Tempo Integral Mestra Bela - de Ensino Fundamental I e II, e o Colégio Estadual Padre Gama - de Ensino Fundamental II e Médio, as quais fizeram parte deste estudo. Para desenvolver este trabalho inicialmente foi realizado levantamento de pessoas com DF que estão estudando ou que já estudaram nas duas escolas estaduais do município, contatados e convidados a participar da pesquisa, assim como suas respectivas mães. Também foram convidados a participar da pesquisa os diretores, coordenadores e professores das referidas escolas. 
Todos os participantes deste estudo assinaram o Termo de Consentimento Livre e Esclarecido antes da obtenção de qualquer informação. Para os menores de idade, o questionário foi aplicado com autorização e acompanhamento do responsável.

Para cada categoria entrevistada (alunos, pais, professores e gestores) foi aplicado um questionário semiestruturado específico, sendo as entrevistas realizadas no período de fevereiro a junho de 2014.

Para os alunos com DF foi registrada sua respectiva idade, sexo e escolaridade. Estes foram questionados quanto ao tempo de diagnóstico da doença, quantas internações por mês, em razão das crises, e da importância da escola e do professor para a sua formação. Também foram questionados se os professores, coordenadores e direção da escola tinham ciência sobre as complicações da DF, sua frequência às aulas em razão das crises e internações, e quais as medidas tomadas pela escola para amparálos.

Para as mães dos alunos com DF o questionário abordou perguntas relacionadas com o tipo de atenção que a escola dispensa aos seus filhos, o conhecimento dos professores e gestores em relação a doença e de como a escola pode ajudar a pessoa com DF.

Este estudo também buscou saber se a escola auxilia o aluno com DF e se os professores disponibilizam atenção especial, quando este é acometido pelos sintomas da doença. O questionário aplicado aos professores, coordenadores e direção, oportunizou o relato das suas experiências em relação ao convívio com os alunos com DF, abordando questões do tipo: o que sabe sobre a doença; leciona ou já lecionou para algum aluno com DF e quando (ano); de que maneira ficou sabendo da existência do aluno com DF, e como pode auxiliar o aluno em relação às faltas pelas crises, com ou sem internação. Ainda, foi questionado acerca de situações de discriminação ou de bullying em relação ao aluno com DF. O professor também foi questionado sobre seu conhecimento em relação às características físicoclínicas do DF e sobre estratégias que poderiam abordar para melhorar o aprendizado desses alunos. Por último, perguntou-se sobre a ciência do decreto Lei $n^{\circ} 1044 / 69$ e do decreto Lei $n^{\circ} .9 .394 / 96$, e se estes são utilizados para amparar o aluno com doença falciforme na escola.

\section{RESULTADOS E DISCUSSÃO}

Neste trabalho foram entrevistados 03 pessoas com DF que frequentam ou já frequentaram a escola, suas respectivas mães, 06 professores, 02 coordenadores e as diretoras das Escola Estadual de Tempo Integral Mestra Bela e o Colégio Estadual Padre Gama.

Em relação aos alunos com $\mathrm{DF}$, um dos entrevistados que está no ensino fundamental II, relatou ter diagnosticado a doença aos 07 anos de idade (ECV, 16 anos). Sua família pertence a uma comunidade quilombola do município e muitos dos seus parentes tiveram ou tem a doença. Ele afirmou que, pelo menos uma vez por mês, precisa de internação hospitalar por causa dos sintomas da doença, e quando se ausenta da escola são realizadas atividades extraclasse. No entanto, reclamou que os professores são indiferentes e não fazem de bom gosto as atividades. Neste sentido, ele cobrou mais cuidado e compreensão dos professores com a situação que enfrenta.

Outro aluno entrevistado disse que a família descobriu que ele tinha DF, com 04 meses de nascido (PHVB, 21 anos). Apesar da idade, ele ainda estuda no Ensino Médio e, segundo ele, por duas vezes ao mês passa por internações. Em razão disso, falta muito às aulas, inclusive por causas das crises de dor, 
necessitando ficar em repouso domiciliar. Ele afirmou que a escola só revê as faltas quando há atestado médico, em razão de internações, mas não considera quando as mesmas são em razão das crises de dor/sem internação. Relatou já ter sofrido bullying na escola, que os professores não dão atenção especial quando ele manifesta algum sintoma da DF em sala, mas que passam os conteúdos que perdeu por motivos de consulta ou internação. Quando questionado como avaliaria o envolvimento da escola com o aluno com DF foi categórico e disse ser péssimo.

O terceiro entrevistado, ex-aluno, diagnosticou a DF com 10 anos de idade (ELM, 28 anos). Ele afirmou que, devido às crises de dor, tem várias internações por mês, mas que já terminou o ensino médio. Este lembrou que quando estudava os professores sempre o ajudavam. Quando questionado sobre o fato de ter DF disse que encara a doença com muita dificuldade, no entanto, acredita que, para que alunos com DF não sejam prejudicados na vida escolar, os professores podem ajudar passando atividade extraclasse.

Quando analisados os depoimentos das mães desses alunos, foi possível perceber nas suas falas uma dose de indignação e insatisfação pela ausência de atitudes da escola. As mães relataram que os professores praticamente ignoram a doença e consideram que as manifestações clínicas não são justificativas para as suas recorrentes faltas. Na visão delas, muitos professores pensam que é preguiça e desinteresse pelas aulas e/ou falta de compromisso. As mães entrevistadas disseram que não há nenhuma divulgação da doença na escola, por isso que, muitos professores a desconhecem e não identificam os sintomas apresentados pelos seus filhos. Classificaram o envolvimento da escola com o aluno em regular ou ruim, ou seja, quase não há envolvimento ou interesse da instituição em entender a doença e afirmaram que a escola sequer auxilia o aluno com DF. Relataram ainda, que os professores não dispensam atenção especial quando o aluno manifesta sintomas da doença na sala de aula/escola, e que já sofreram discriminação por causa da doença. Para elas, isso ocorre pela falta de conhecimento dos sintomas e complicações da doença, por parte dos professores, coordenadores e direção.

As entrevistas também foram realizadas com seis professores da Rede Estadual de Ensino do Colégio Estadual Padre Gama, os professores da Escola Estadual de Tempo Integral Mestra Bela não autorizaram a sua participação. Os seis professores que participaram da pesquisa informaram ter ministrado aulas para alunos com DF, mas somente dois destes, formados em Ciências Biológicas, relataram conhecer a doença, suas características e sintomas. Todos os professores entrevistados disseram que os alunos com DF faltam muito às aulas, alegando sentir dor, desânimo, fraqueza e cansaço. Eles percebem que estes alunos apresentam olhos com tom amarelado e palidez na pele. Quando questionado a um dos professores o que sabe sobre doença falciforme, este respondeu em um tom inocente e simplista: "que essa doença poderia não existir assim como as outras". Outro questionamento que eles responderam unanimemente foi que "o aluno não sofre discriminação dos colegas em sala de aula por causa da doença falciforme". Somente um dos professores disse ter conhecimento dos decretos de Lei no 1044/69 e 9.394/96, e que estes são utilizados para amparar os alunos com DF na escola, já os demais professores não se referiram às leis.

$\mathrm{Na}$ entrevista com as gestoras, a diretora da Escola de Tempo Integral (E.R.S), que é gestora há 09 anos, disse que já ouviu falar sobre a DF e que, o aluno com a doença, que se matricula na escola, recebe atenção diferenciada, com atendimento domiciliar, atividades extraclasse, sendo avaliado 
através da aplicação de provas, testes, trabalhos, entre outros procedimentos avaliativos.

A diretora da escola de Ensino Médio (I.G.O.), gestora há 06 anos na mesma, disse conhecer a doença e que o aluno com DF que frequenta sua unidade escolar possui dificuldade de aprendizagem e por isso, participa da sala de recurso multifuncional. A mesma disse ser possível adequar as faltas do aluno com DF, através de uma reclassificação, e, quando questionada se os decretos de Lei 1044/69 e 9.394/96 são utilizados para amparar os alunos com DF, sua resposta foi afirmativa.

Também foram entrevistadas as coordenadoras de ambas as escolas. A Coordenadora (C.O.L.G) da Escola em Tempo Integral foi sucinta em suas respostas. Ela afirmou que, quando o aluno com DF precisou de atenção especial, por causa das manifestações clínicas da doença, foi realizado acompanhamento individual das suas atividades. No seu ponto de vista, a escola pode melhorar a qualidade do ensino desses alunos através da aplicação de trabalhos individuais. De modo similar, a coordenadora colocou que, para compensar as faltas, são aplicadas atividades extraclasse, com acompanhamento pedagógico.

A coordenadora do Colégio Estadual Padre Gama (E.M.A.C), relatou que o aluno com DF que frequenta a escola é atendido com aulas diferenciadas e atividades extraclasse. No entanto, ressaltou que há resistência por parte dos professores, do aluno e dos seus pais com esse procedimento. Segundo a coordenadora, esta é a melhor maneira da escola contribuir para melhorar a formação dos alunos com DF, porém, admitiu que os professores só fazem acompanhamento mediante um laudo médico e com atestado acima de 15 dias.

Diferente do discurso das mães dos alunos com DF, os professores e gestores das duas escolas de Monte do Carmo declararam que as mesmas realizam acompanhamento diferenciado para estes alunos. É importante destacar que o acompanhamento diferenciado para o aluno com DF deve ser realizado diariamente, a fim de, estimulá-lo a vencer as limitações da doença no ambiente de ensino e não somente na tentativa de suprir suas faltas escolares.

A escola possui papel fundamental no processo de aprendizado do aluno com DF. Para atender às necessidades desse aluno, os profissionais da educação precisam conhecer a doença e proporcionar um ambiente mais confortável e propício para o aprendizado (RODRIGUES et al., 2014).

A manifestação clínica mais comum da pessoa com DF são as crises de dor. Estas são causadas pela falcização dos glóbulos vermelhos, o que desencadeia a vaso oclusão, prejudicando a circulação sanguínea e a oxigenação dos tecidos. O excesso de exercício físico, exposição exagerada ao frio e ao calor, estresse e variação brusca de temperatura são fatores que podem desencadear o processo de falcização dos glóbulos vermelhos (NAOUM e DOMINGOS, 1997; NAOUM, 2000).

As crises de dor são um dos sintomas que mais exigem cuidados imediatos. E, se tratando de aluno, quando estiver em sala de aula, o professor pode, neste contexto, observar mudanças no comportamento. Em situação de dor, há alunos que ficam mais quietos e calados, não revelando o que estão sentindo. Outros, no entanto, podem ficar irritadiços, impacientes e agressivos. De modo que, cada pessoa age de um jeito e, neste sentido, é importante deixar à vontade o aluno para que ele tenha a coragem de falar o que está sentindo. A doença é uma condição especial que vai exigir certos cuidados, mas que não necessariamente exercerá impacto negativo no desenvolvimento cognitivo e psicossocial do aluno (DIAS et al., 2013; RODRIGUES et al, 2014). 
Portanto, a humanização do ambiente escolar para acolher bem o aluno com DF é tão necessária quanto é a humanização do sistema de saúde para a realização do tratamento. A implicação do quadro clínico da doença sobre a aprendizagem da criança merece atenção na escola. A escola é um ambiente oportuno para o fortalecimento do vínculo entre o aluno, os professores e seus colegas, podendo reverter a situação da criança no ambiente escolar (RODRIGUES et al., 2014). A frequência às aulas deve ser estimulada para a socialização do aluno com a doença, que frequentemente se vê isolado.

Aqui, nesse trabalho, as pessoas com DF relataram suas dificuldades em frequentar o ambiente escolar, devido ao quadro clínico que a doença apresenta. Os sintomas da DF atrapalham o desempenho das funções escolares, visto que a pessoa com DF precisa de afastamento constante de suas atividades, o que afeta diretamente seu desempenho (PIRES, 2008; DIAS et al., 2013).

Quando há a necessidade de internação do aluno, a classe hospitalar, também pode atuar como uma modalidade de atendimento pedagógico. A fim de, primar pela garantia da continuidade dos estudos dos alunos que são hospitalizados, interrompendo momentaneamente o acesso à escola. Deste modo, para o aluno hospitalizado é indicado que a escola entre em contato com a família e a classe hospitalar, encaminhando as atividades e assuntos debatidos em sala de aula, durante o período no qual o aluno está afastado (KIKUCHI, 2003).

Esses procedimentos são de grande valia para o aluno e tem amparo legal, por isso é extremamente necessário a comunicação entre escola e família, para que os professores sejam informados sobre a situação do aluno. De posse dessas informações os professores devem elaborar um plano de estudos adaptados à realidade do aluno naquele momento, seguindo as diretrizes da Lei $n^{\circ}$. 9349/96.
Matricular o aluno com DF na escola pública ou privada não é o suficiente, é necessário fazer com que seus direitos de cidadania, de apropriação e construção do conhecimento sejam exercidos e garantidos, observando de forma especial suas necessidades médicas e educacionais especiais.

$\mathrm{O}$ aluno com DF pode vir a faltar às aulas, devido aos períodos de tratamento ou de internação, o que pode gerar 40 ou 50 dias de falta por ano letivo (KIKUCHI, 2003). Estas ausências poderão atrapalhar o desenvolvimento escolar do aluno, ocasionando abandono ou reprovação, e dificuldades para realizar as atividades e avaliações sobre os termos aplicados em sala de aula. Neste sentido, a figura do professor é de suma importância, pois conhecendo a doença, os sintomas e a realidade do aluno, certamente poderá adotar mecanismos de avaliação que o alcance.

Entende-se aqui que a avaliação não é um fim em si mesmo, os meios avaliativos realizados pelo professor podem ratificar uma das orientações dos Parâmetros Curriculares Nacionais quando falam a respeito da tomada de consciência do aluno, quanto às suas dificuldades, conquistas, potencialidades e possibilidades de reorganizar seus investimentos no desafio de aprender (SECRETARIA DE EDUCAÇÃO FUNDAMENTAL, 97).

Assim, o aluno com DF apresenta dificuldades de ordem psicológica e produtiva em razão das restrições e limitações impostas pelos sintomas da doença, forçando-o ao afastamento provisório das aulas, mas ele apresenta o mesmo potencial intelectual de uma pessoa normal (KIKUCHI, 2003).

Portanto, este trabalho suscita uma carência de informação e formação do corpo docente e pedagógico das unidades escolares de Monte do Carmo, em relação a DF. Diante disso, observa-se que há uma necessidade urgente da formação 
continuada de professores para atuar no atendimento destes alunos.

\section{CONCLUSÃO}

Diante do exposto, percebe-se que os alunos com DF não são plenamente atendidos em suas necessidades e direitos. Muitas vezes, são lesados no seu dia a dia escolar em razão das suas ausências às aulas, devido aos sintomas da doença. $O$ que se constatou é que muitas vezes esses alunos não têm a oportunidade de usufruir de uma aprendizagem satisfatória por não serem bem acompanhados em suas necessidades cognitivas, pessoais e escolares.

O presente trabalho contribuiu para abrir um espaço de discussão sobre este tema nas escolas, levando os profissionais de educação e as famílias dos alunos com DF a estarem mais próximos, compartilhando das preocupações e dificuldades enfrentadas pelos alunos, em sala de aula e no cotidiano.

Deixamos aqui as primeiras contribuições sobre o assunto, nas escolas públicas de Monte do Carmo e, consequentemente, do estado do Tocantins. O certo é que há um longo caminho a ser percorrido até que o aluno com DF possa usufruir de uma formação escolar adequada para a sua condição, o que influenciará definitivamente para o seu bem estar social e pessoal. Para tanto, esse resultado passa impreterivelmente pelo ambiente escolar, o que exigirá um novo olhar dos professores e a instrumentalização das escolas com boas práticas de inclusão para tais alunos.

Todos os autores declararam não haver qualquer potencial conflito de interesses referente a este artigo.

\section{REFERÊNCIAS}

Lei $n^{\circ} .1 .044$, de 21 de outubro de 1969, Dispõe sobre tratamento excepcional para os alunos portadores das afecções que indica. Brasília, 21 out.
1969.

Disponível

em:

http://www.planalto.gov.br/ccivil_03/decreto-

lei/Del1044.htm. Acesso em 05 de janeiro de 2017.

Lei $n^{\circ}$. 9.394, de 20 de dezembro de 1996. Estabelece as Diretrizes e Bases da Educação Nacional. Diário Oficial [da] República Federativa do Brasil, 23 de dezembro de 1996. Disponível em: http://portal.mec.gov.br/arquivos/pdf/ldb.pdf. Acesso em 05 de janeiro de 2017.

ANDRADE, S. P.; TELES, A.F.; SOUZA, L.O.; SILVA, L.C.; OLIVEIRA, R.J.; SANTOS, M.G.; SEIBERT, C.S. A distribuição da hemoglobina $S$ em três comunidades quilombolas doestado do Tocantins-Brasil. Scientia Amazônia. v.4, n.1, p.1020, 2015.

BRASIL. Ministério do Planejamento, Orçamento e Gestão. Instituto Brasileiro de Geografia e Estatística. Contagem Populacional. Disponivel em:

<>http://cidades.ibge.gov.br/painel/populacao.php?co dmun=1713>. Acesso em: agosto de 2016.

BRASIL. Constituição dos Estados Unidos do Brasil. Rio de Janeiro, 1946. Disponível em: http://www.planalto.gov.br/ccivil.03.03/constituicao/ constituicao46.htm. Acesso em 05 de janeiro de 2017.

DI NUZZO, D.V.P.; FONSECA, S.F. Anemia falciforme e infecções. Jornal de Pediatria, v.80, n.5, p.347-354, 2004.

DIAS, T.L.; EMUNO, S.R.F.; FRANÇA, J.A.; NASCIMENTO, R.C.L.C.B. A saúde da criança com doença falciforme: desempenho escolar e cognitivo. R. Educ. Públ. Cuiabá, v.22, n.49, p.575-594, 2013.

FUNDAÇÃO CULTURAL PALMARES. Comunidades Certificadas. Certidões Expedidas às Comunidades Remanescentes de Quilombos (CRQs) Atualizada até a Portaria $\mathrm{N}^{\circ}$ - 104/2016, Publicada no DOU de 20/05/2016. 2016. Disponível em: http://www.palmares.gov.br/wpcontent/uploads/2016/06/COMUNIDADESCERTIFICADAS.pdf. Acesso em 29 dez. 2016.a

FUNDAÇÃO CULTURAL PALMARES. Em análise Técnica. Comunidades Remanescentes de Quilombos (CRQs) com Processo de Certificação em Andamento: aguardando complementação de documentação - atualizada até 20/05/2016. 2016. Disponível em: http://www.palmares.gov.br/wpcontent/uploads/2016/06/COMUNIDADES-EMAN\%C3\%81LISE.pdf. Acesso em 29 dez. 2016.b 
KIKUCHI, B. A. Anemia Falciforme: manual para agente da educação e saúde. $2^{\mathrm{a}}$ ed. Belo Horizonte, Editora Health.80p, 2003.

NAOUM, P.C. Interferentes eritrocitários e ambientais na anemia falciforme. Revista Brasileira Hematologia e Hemoterapia, v.22, n.1, p.05-22, 2000.

NAOUM, P.C; DOMINGOS, C.R.B. Doenças falciformes no Brasil. Origem, genótipos, haplótipos e distribuição geográfica. Jornal Brasileiro de Patologia, v.33, n.3, p.145-153, 1997.

PAIVA-SILVA, R.B.; RAMALHO, A.S.; CASSORLA, R.M.S. A anemia falciforme como problema de Saúde Pública no Brasil. Revista Saúde Pública, v.27, n.1, p.54-58, 1993.

PIRES,C.M.M.V. Anemia Falciforme: Importância do entendimento e responsabilidade do educador na formação do aluno. Autorais: Cuiabá: UNIC Departamento de Ciências Biológicas, 2008/2.
RAMALHO, A.S.; MAGNA, L.A. Portaria n ${ }^{\circ}$ 822/01 do Ministério da Saúde e as peculiaridades das hemoglobinopatias em saúde pública no Brasil. Caderno de Saúde Pública, v.19, n.4, p.1195-1199, 2003.

RODRIGUES, A.S.N; SILVA, L.V.; VILHENA, M.; SOUZA, W. O aluno com doença falciforme e a escola. Cadernos de Pesquisa em Educação. v.19, n.40, p.130-137. 2014.

SECRETARIA DE EDUCAÇÃO FUNDAMENTAL. Parâmetros curriculares nacionais: introdução aos parâmetros curriculares nacionais. Brasília: MEC/SEF, 1997. 126p.

ZAGO, M.A.; PINTO, A.C.S. Fisiopatologia das doenças falciformes: da mutação genética à insuficiência de múltiplos órgãos. Revista Brasileira de Hematologia e Hemoterapia, v.29, n.3, p.207214 , 2007. 